\title{
molecules
}

ISSN 1420-3049

http://www.mdpi.org

Review

\section{Development of Fluorous Lewis Acid-Catalyzed Reactions}

\author{
Akihiro Yoshida ${ }^{1, \dagger}$, Xiuhua Hao ${ }^{1}$, Osamu Yamazaki ${ }^{2}$ and Joji Nishikido ${ }^{2, *}$ \\ 1 The Noguchi Institute, Itabashi-ku, Tokyo 173-0003, Japan; ${ }^{\dagger}$ e-mail: ayoshida@noguchi.or.jp \\ 2 Asahi Kasei Corporation, Fuji, Shizuoka 416-8501, Japan \\ * Author to whom correspondence should be addressed; e-mail: nishikido.jc@om.asahi-kasei.co.jp
}

Received: 5 July 2006; in revised form: 26 July 2006 / Accepted: 26 July 2006 / Published: 23 August 2006

\begin{abstract}
Organic synthetic methodology in the 21st century aims to conform to the principles of green sustainable chemistry (GSC) and we may expect that in the future, the realization of GSC will be an important objective for chemical industries. An important aim of synthetic organic chemistry is to implement waste-free and environmentally-benign industrial processes using Lewis acids as versatile as aluminum choride. A key technological objective of our work in this area has been to achieve a "catalyst recycling system that utilizes the high activity and structural features of fluorous Lewis acid catalysts". Thus, we have developed a series of novel fluorous Lewis acid catalysts, namely the ytterbium(III), scandium(III), tin(IV) or hafnium(IV) bis(perfluoroalkanesulfonyl)amides or tris(perfluoro- alkanesulfonyl)methides. Our catalysts are recyclable and effective for acylations of alcohols and aromatics, Baeyer-Villiger reactions, direct esterifications and transesterifications in a fluorous biphasic system (FBS), in supercritical carbon dioxide and on fluorous silica gel supports.
\end{abstract}

Keywords: Fluorous chemistry, Lewis acid, sulfonimide, biphasic system, aqueous reaction.

\section{Contents}

1. Introduction

2. Fluorous Lewis Acid Catalysts

3. Fluorous Biphasic Catalysis by Fluorous Lewis Acids

4. Fluorous Biphasic Reactions Containing Water 
5. Continuous-flow Reaction in FBS

6. Fluorous Silica Gel-Supported Lewis Acid Catalysts

7. Supercritical Carbon Dioxide as a Reaction Medium

8. Conclusions

\section{Introduction}

Lewis acid-mediated reactions using aluminum chloride typically yield large amounts of acidic wastes along with the desired product(s). With this in mind, we sought to develop novel reaction processes catalyzed by highly active, selective and recyclable Lewis acids that would significantly reduce these acidic wastes and could thus be used to replace existing aluminum chloride processes. Socalled "fluorous chemistry" [1] has been studied since 1994, when Horváth and Rábai first reported fluorous biphasic catalysis [2]. Lively discussions on this topic occurred at the 1st International Symposium on Fluorous Technologies (ISoFT), held in Bordeaux (France) in July 2005, which was attended by chemists from 15 countries and highlighted by Chemical \& Engineering News [3]. We review herein a series of fluorous biphasic reactions catalyzed by fluorous Lewis acids containing a large number of fluorine atoms, heterogeneous Lewis acid-catalyzed reactions using fluorous silica gel-supported fluorous Lewis acids and fluorous Lewis acid-catalyzed reactions in supercritical carbon dioxide.

\section{Fluorous Lewis Acid Catalysts}

Kobayashi and co-workers have recently reported that lanthanide(III) triflates can be used as waterstable Lewis acid catalysts [4]. In 1994, Koppel, Taft et al. predicted that perfluorobutanesulfonimide $\left[\left(n-\mathrm{C}_{4} \mathrm{~F}_{9} \mathrm{SO}_{2}\right)_{2} \mathrm{NH}\right]$ and tris(perfluorobutanesulfonyl)methane $\left[\left(n-\mathrm{C}_{4} \mathrm{~F}_{9} \mathrm{SO}_{2}\right)_{3} \mathrm{CH}\right]$ would have much higher acidity than trifluoromethanesulfonic acid $\left(\mathrm{CF}_{3} \mathrm{SO}_{2} \mathrm{OH}\right)$ [5]. Thus, it was expected that Lewis acid bearing conjugate bases of these compounds as ligands could be more active than the corresponding metal triflates.

Meanwhile, we have been actively involved in the discovery and development of stronger and water-stable Lewis acid catalysts, and have successfully prepared and developed novel fluorous Lewis acid catalysts $\left[\left(\mathrm{Ln}\left[\mathrm{N}\left(\mathrm{SO}_{2}-n-\mathrm{C}_{8} \mathrm{~F}_{17}\right)_{2}\right]_{3}\right.\right.$ and $\left.\left.\mathrm{Ln}\left[\mathrm{C}\left(\mathrm{SO}_{2}-n-\mathrm{C}_{8} \mathrm{~F}_{17}\right)_{3}\right]_{3}\right)\right]$, like those described above, using ytterbium(III) and scandium(III) as central metals, which can be highly active catalysts in FriedelCrafts acylation, Diels-Alder, Meerwein-Ponndorf-Verley reduction and esterification reactions [6]. Whereas metal triflate catalysts are generally water-soluble, our catalysts are water-repellent and highly "fluorous" due to the perfluoroalkyl chains surrounding the central metal. The next topic of interest was recycling of these catalysts, which is an important feature for industrial processes. Thus, we examined various reactions under fluorous biphasic catalysis, heterogeneous reactions catalyzed by fluorous silica gel-supported fluorous Lewis acid catalysts and fluorous Lewis acid-catalyzed reactions in supercritical carbon dioxide. 


\section{Fluorous Biphasic Catalysis by Fluorous Lewis Acids}

Fluorous solvents such as perfluoroalkanes are sparingly soluble in general organic solvents and water. On the other hand, fluorous catalysts bearing highly fluorinated ligands are also sparingly soluble in general organic solvents, but they are soluble in fluorous solvents. As mentioned above, Horváth and Rábai introduced the concept of a fluorous biphasic system (FBS, Figure 1) in 1994, when they reported hydroformylation in organic and fluorous solvents catalyzed by a rhodium(I) catalyst bearing fluorous ligands [2]. Since then, a number of fluorous catalysts have been prepared, although almost all of these catalysts were transition metal complexes bearing perfluoroalkyl group ligands connected through hydrocarbon spacers. In contrast, we were the first to develop lanthanide(III) tris(perfluoroalkanesulfonyl)methides $\left(\mathrm{Ln}\left[\mathrm{C}\left(\mathrm{SO}_{2}-n-\mathrm{C}_{8} \mathrm{~F}_{17}\right)_{3}\right]_{3}\right)$ and bis(perfluoroalkanesulfonyl)amides $\left(\mathrm{Ln}\left[\mathrm{N}\left(\mathrm{SO}_{2}-n-\mathrm{C}_{8} \mathrm{~F}_{17}\right)_{2}\right]_{3}\right)$ bearing no hydrocarbon spacers for fluorous biphasic catalysis.

Figure 1. Fluorous biphasic catalysis.

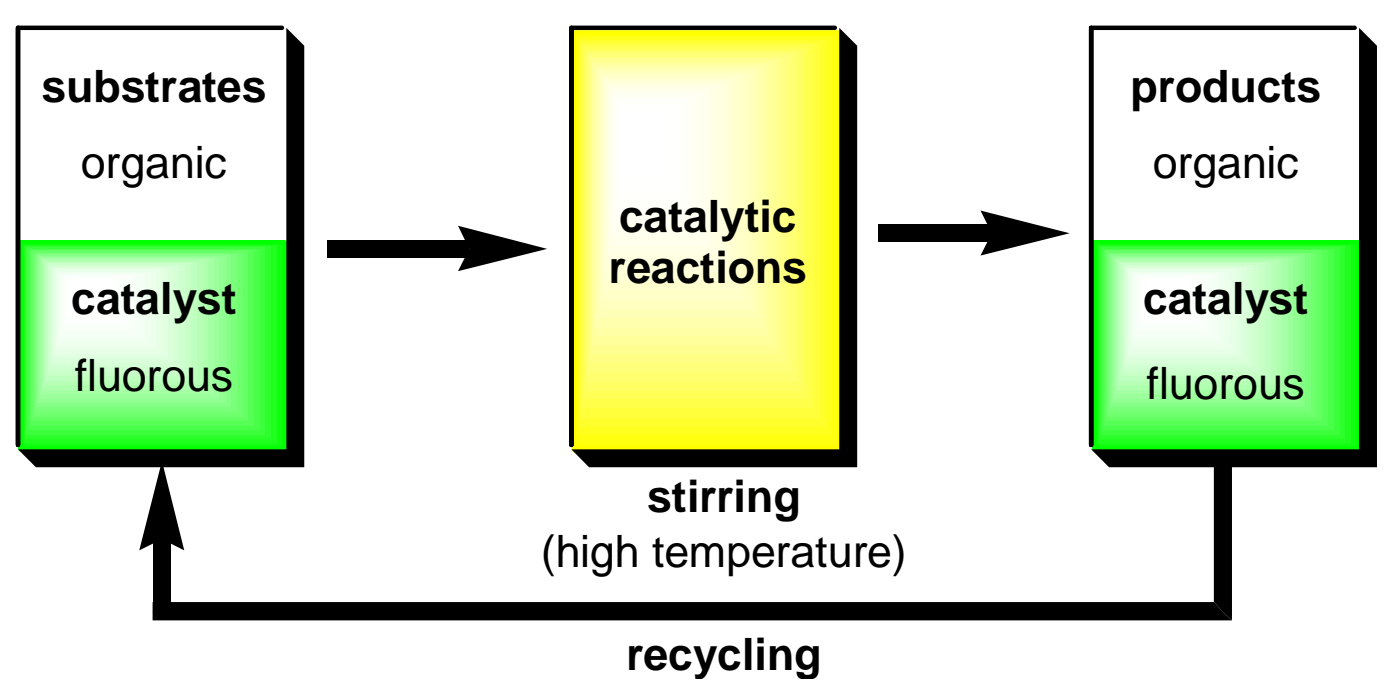

Considering that lanthanide complexes with fluorous ligands with long-chain fluorous ponytails and no hydrocarbon spacers would be both strongly Lewis acidic and highly fluorous for use in FBS, we prepared several fluorous Lewis acids (such as $\mathrm{Hf}(\mathrm{IV}), \mathrm{Sn}(\mathrm{IV}), \mathrm{Bi}(\mathrm{III})$ ) and examined their utilities in fluorous biphasic reactions [7].

Initially, we studied acetylation reactions of cyclohexanol in toluene/perfluoro(methylcyclohexane) catalyzed by $1 \mathrm{~mol} \%$ of $\mathrm{Yb}\left[\mathrm{C}\left(\mathrm{SO}_{2}-n-\mathrm{C}_{8} \mathrm{~F}_{17}\right)_{3}\right]_{3}$ or $\mathrm{Sc}\left[\mathrm{C}\left(\mathrm{SO}_{2}-n-\mathrm{C}_{8} \mathrm{~F}_{17}\right)_{3}\right]_{3}$ (Table 1$)$. These reactions proceeded quantitatively in the heterogeneous solution under vigorous stirring. After the reaction, the reaction mixture separated into two phases upon standing. The lower fluorous phase, containing the fluorous catalyst, was recovered and reused up to five times without any loss of catalytic activity. On the other hand, the upper organic phase was shown by ICP analysis to contain $<2 \mathrm{ppm}$ of metal. Thus, the fluorous catalyst was almost completely immobilized in the fluorous phase. 
Table 1. Fluorous biphasic acetylation.

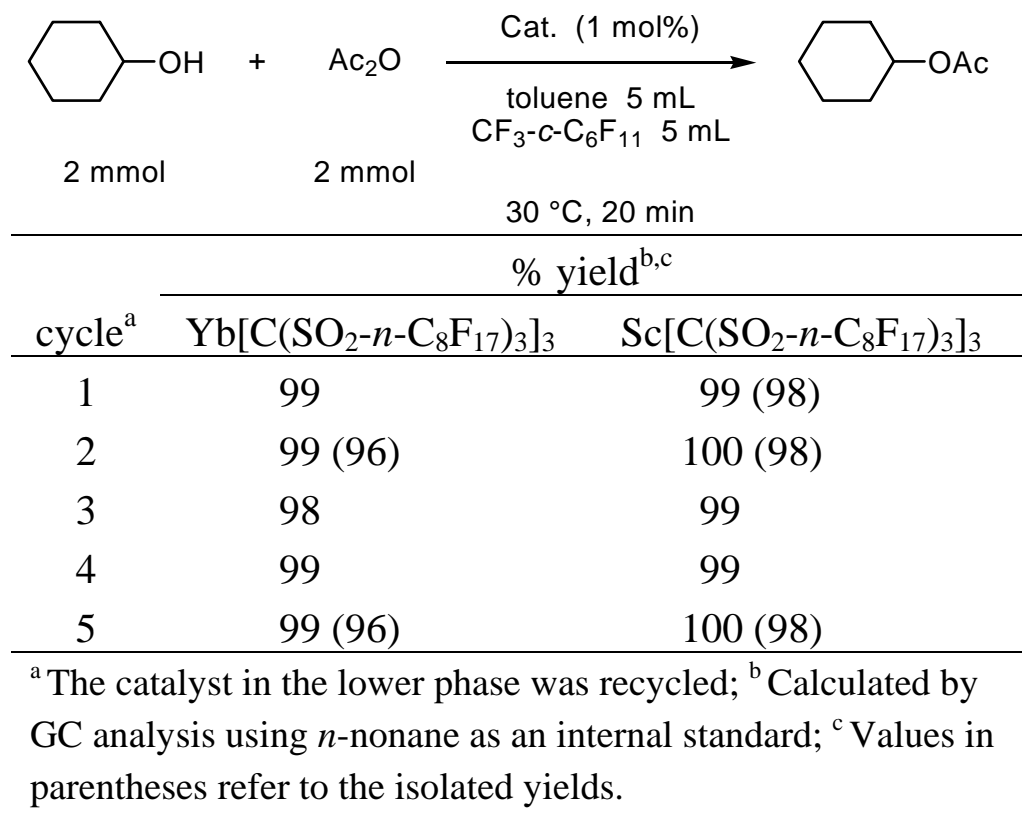

We have also reported that fluorous Lewis acid catalysts were both useful and recyclable in carboncarbon bond forming reactions such as the Diels-Alder reaction, the Mukaiyama aldol reaction [8] and Friedel-Crafts acylations [9]. In particular, classical Friedel-Crafts acylation generally requires the use of an equimolar or greater amount of a catalyst such as aluminum chloride, whereas on the contrary, Friedel-Crafts acylation of anisole and related aromatic compounds proceeded smoothly in chlorobenzene/GALDEN ${ }^{\circledR}$ SV135 [10] using only 1 mol\% of $\mathrm{Hf}\left[\mathrm{N}\left(\mathrm{SO}_{2}-n-\mathrm{C}_{8} \mathrm{~F}_{17}\right)_{2}\right]_{4}$, which was more active than $\mathrm{Hf}(\mathrm{OTf})_{4}$ (Table 2). As expected, this catalyst was also recyclable. Toluene and even chlorobenzene could be used as both nucleophilic aromatics and solvents [9].

Table 2. Fluorous biphasic Friedel-Crafts acylation.

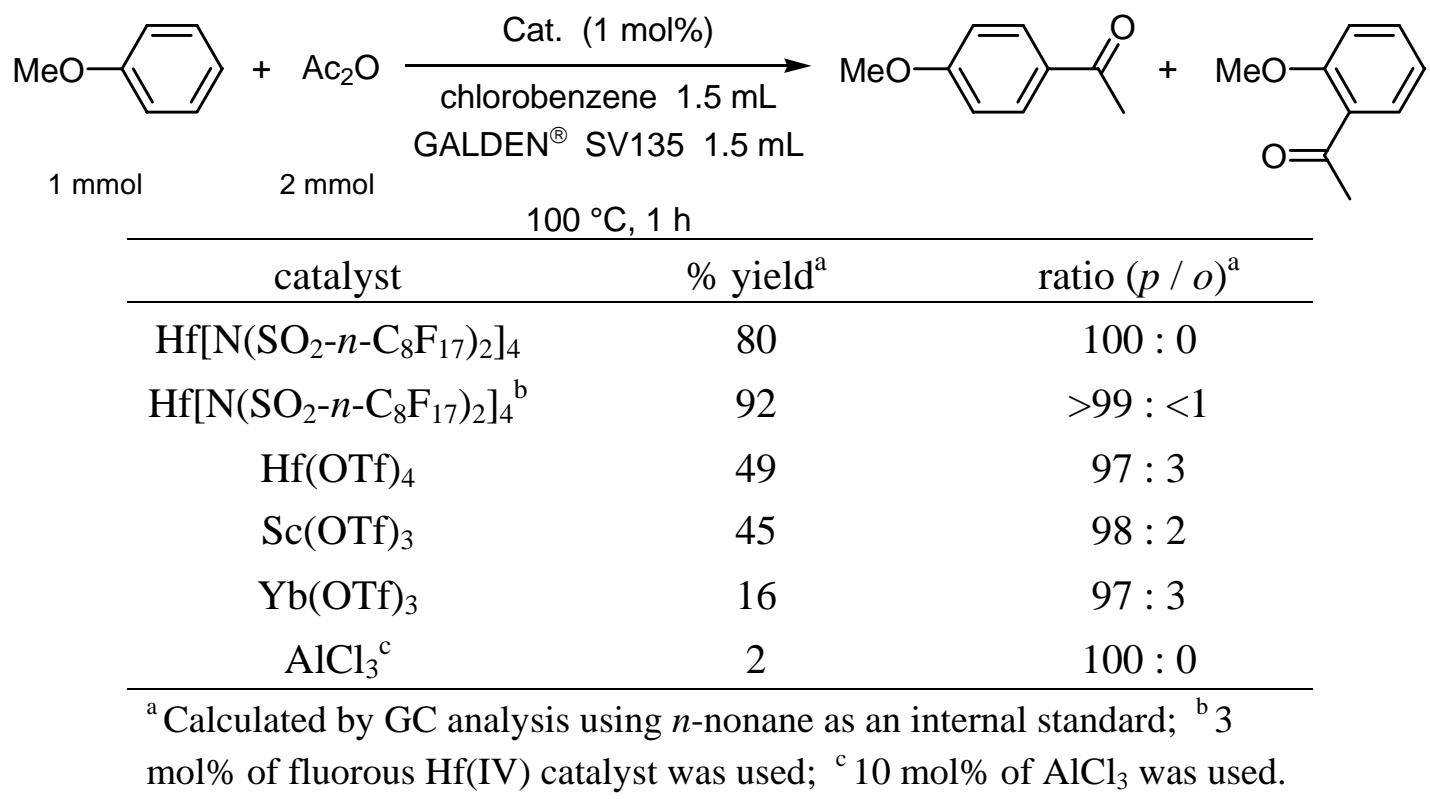

Recently, we have clarified that lanthanide(III) with $\mathrm{N}\left(\mathrm{SO}_{2}-\mathrm{C}_{10} \mathrm{HF}_{20} \mathrm{O}_{3}\right)_{2}$ ligands, including ether oxygen atoms, also behave as highly active fluorous Lewis acids [11]. 


\section{Fluorous Biphasic Reactions Containing Water}

Our fluorous Lewis acid catalysts, which catalyze several reactions at the organic/fluorous interface, are stable to water due to their highly water-repellent properties. It was therefore considered that fluorous Lewis acid catalysts could be used even in water-containing reaction systems.

At first, we examined direct esterification reactions [12] using $\mathrm{Hf}\left[\mathrm{N}\left(\mathrm{SO}_{2}-n-\mathrm{C}_{8} \mathrm{~F}_{17}\right)_{2}\right]_{4}$ as catalyst. The catalytic reactions of an equimolar amount of carboxylic acid and alcohol proceeded under mild conditions $\left(<100{ }^{\circ} \mathrm{C}\right)$ without distilling off the water formed as a by-product (Table 3) [13]. The hafnium(IV) catalyst was recyclable, as expected. It was thought that water rapidly moved out of the reactive site at the organic/fluorous interface, since water is inmiscible in both the organic and fluorous phases.

Table 3. Direct esterification of carboxylic acid and alcohol.

\begin{tabular}{|c|c|c|c|c|}
\hline \multirow{2}{*}{$\begin{array}{r}\mathrm{R}^{1} \mathrm{CO}_{2} \mathrm{H} \\
1 \mathrm{mmol} \\
\end{array}$} & \multirow[t]{2}{*}{$\mathrm{R}^{2} \mathrm{OH}$} & $\begin{array}{c}\mathrm{Hf}\left[\mathrm{N}\left(\mathrm{SO}_{2}-n-\mathrm{C}_{8} \mathrm{~F}_{17}\right)_{2}\right]_{4} \\
(5 \mathrm{~mol} \%)\end{array}$ & \multirow[t]{2}{*}{$\mathrm{R}^{1} \mathrm{CO}_{2} \mathrm{R}^{2}$} & \\
\hline & & $\begin{array}{l}\mathrm{ClCH}_{2} \mathrm{CH}_{2} \mathrm{Cl} 3 \mathrm{~mL} \\
\mathrm{CF}_{3}-\mathrm{C}-\mathrm{C}_{6} \mathrm{~F}_{11} 3 \mathrm{~mL}\end{array}$ & & \\
\hline $\mathrm{R}^{1} \mathrm{CO}_{2} \mathrm{H}$ & $\mathrm{R}^{2} \mathrm{OH}$ & conditions & $\%$ yield $^{\mathrm{a}}$ & $\%$ selectivity ${ }^{\mathrm{b}}$ \\
\hline $\mathrm{AcOH}$ & $c-\mathrm{C}_{6} \mathrm{H}_{11} \mathrm{OH}$ & $50^{\circ} \mathrm{C}, 8 \mathrm{~h}$ & 82 & 98 \\
\hline$c-\mathrm{C}_{6} \mathrm{H}_{11} \mathrm{CO}_{2} \mathrm{H}$ & $n-\mathrm{C}_{4} \mathrm{H}_{9} \mathrm{OH}$ & $70^{\circ} \mathrm{C}, 15 \mathrm{~h}$ & 92 & 97 \\
\hline$c-\mathrm{C}_{6} \mathrm{H}_{11} \mathrm{CO}_{2} \mathrm{H}$ & $\mathrm{PhCH}_{2} \mathrm{OH}$ & $50^{\circ} \mathrm{C}, 24 \mathrm{~h}$ & 89 & 98 \\
\hline$c-\mathrm{C}_{6} \mathrm{H}_{11} \mathrm{CO}_{2} \mathrm{H}$ & $c-\mathrm{C}_{6} \mathrm{H}_{11} \mathrm{OH}$ & $50^{\circ} \mathrm{C}, 24 \mathrm{~h}$ & 55 & 98 \\
\hline $\mathrm{PhCO}_{2} \mathrm{H}$ & $n-\mathrm{C}_{4} \mathrm{H}_{9} \mathrm{OH}$ & $90{ }^{\circ} \mathrm{C}, 15 \mathrm{~h}^{\mathrm{c}}$ & 85 & 96 \\
\hline $\mathrm{CH}_{2}=\mathrm{CH}\left(\mathrm{CH}_{3}\right) \mathrm{CO}_{2} \mathrm{H}$ & $\mathrm{CH}_{3} \mathrm{OH}^{\mathrm{d}}$ & $60^{\circ} \mathrm{C}, 8 \mathrm{~h}$ & 86 & 98 \\
\hline
\end{tabular}

${ }^{\mathrm{a}}$ Calculated by GC analysis using $n$-nonane as an internal standard; ${ }^{\mathrm{b}}$ Molar ratio of formed ester / converted acid; ${ }^{\mathrm{c}} \mathrm{In} \mathrm{ClCH}_{2} \mathrm{CH}_{2} \mathrm{Cl}(3 \mathrm{~mL}) /$ perfluorodecalin $(3 \mathrm{~mL}) ;{ }^{\mathrm{d}} 5 \mathrm{mmol}$ of methanol were used.

The Baeyer-Villiger reaction is a useful method for synthesis of esters or lactones from ketones. It was also known that to carry out this reaction ketones typically have to be treated with a stoichiometric amount of a potentially explosive concentrated organic peracid such as peracetic acid or perbenzoic acid. As a result we developed an environmentally benign Baeyer-Villiger oxidation with commercially available and less explosive 35\% aqueous hydrogen peroxide solution, using our fluorous catalysts. From an examination of various catalysts, it was found that $\mathrm{Sn}\left[\mathrm{N}\left(\mathrm{SO}_{2}-n-\mathrm{C}_{8} \mathrm{~F}_{17}\right)_{2}\right]_{4}$ was the most effective catalyst for lactonization of cyclic ketones such as 2-adamantanone (Table 4) [14].

The fluorous tin(IV) catalyst was recyclable and even after the 4th cycle reaction, the high yields and selectivity were maintained. It was also found that the FBS reaction displayed better selectivity than a single phase system. Furthermore, fluorous amide catalysts were more active than the corresponding triflate catalysts. The fluorous tin(IV) catalyst was also effective for transesterification [14]. 
Table 4. Baeyer-Villiger reactions with aqueous $\mathrm{H}_{2} \mathrm{O}_{2}$.

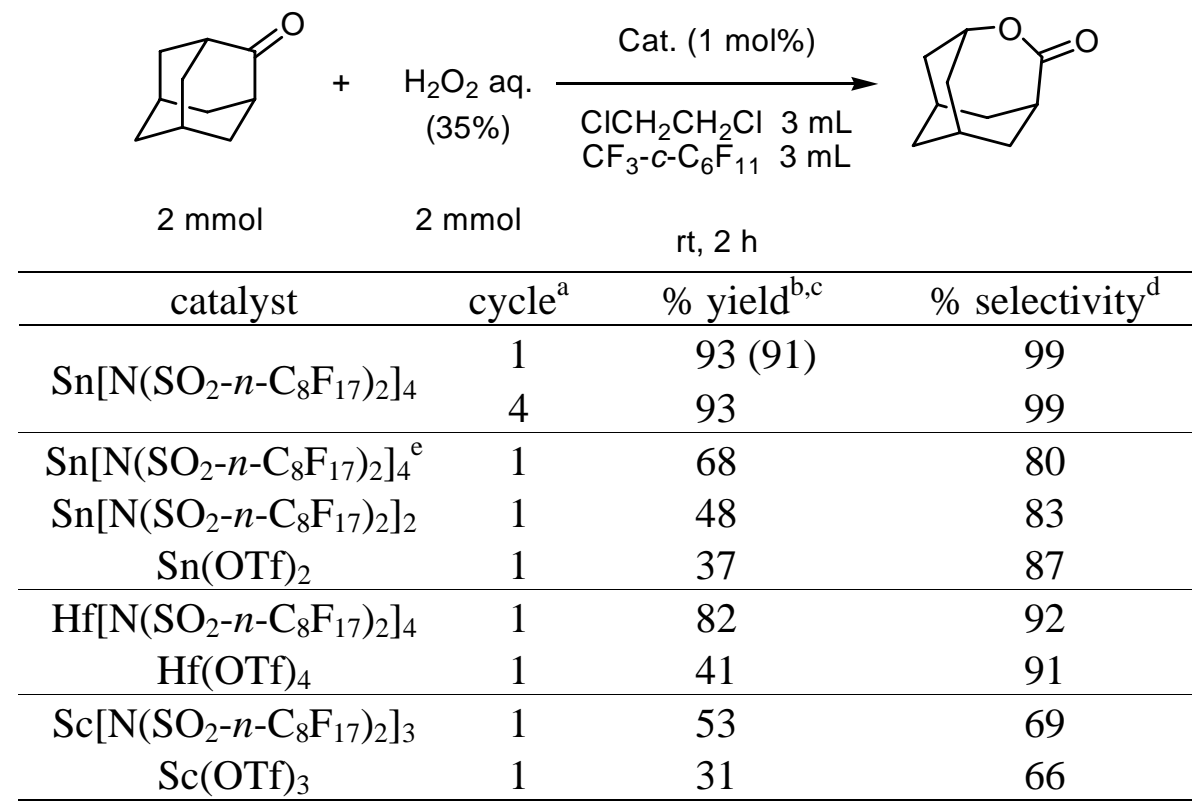

${ }^{\mathrm{a}}$ The catalyst in the lower phase was recycled. ${ }^{\mathrm{b}}$ Calculated by GC analysis using $n$-nonane as an internal standard. ${ }^{\mathrm{c}}$ Values in parentheses refer to the isolated yields. ${ }^{\mathrm{d}}$ Molar ratio of formed lactone / converted

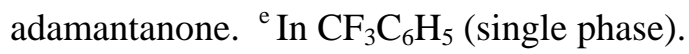

\section{Continuous-flow Reaction in FBS}

The density of fluorous solvents is higher than that of common organic solvents. Based on this fact we designed novel continuous-flow reaction apparatus, which consisted of a reactor equipped with a mechanical stirrer and a decanter (Figure 2). The fluorous solvent is poured into the reactor, followed by addition of a fluorous catalyst such as $\mathrm{Yb}\left[\mathrm{N}\left(\mathrm{SO}_{2}-\mathrm{C}_{10} \mathrm{HF}_{20} \mathrm{O}_{3}\right)_{2}\right]_{3}$, which is immobilized in the fluorous solution because of its insolubility in general organic solvents. The organic solution containing organic substrates and reagents as the mobile organic phase flows continuously into the reactor where it is vigorously stirred with the stationary fluorous phase. The reactions proceed in the resultant emulsion. After the reaction, the emulsion mixture is automatically introduced to the decanter where the organic-fluorous phases are separated. The upper organic phase containing the product(s) overflows and is collected while the lower fluorous phase is recycled and thus, the substrates can be readily converted to the products through this continuous-flow system. This technique is of importance for application to industrial processes. We performed the acetylation of cyclohexanol with acetic anhydride catalyzed by $\mathrm{Yb}\left[\mathrm{N}\left(\mathrm{SO}_{2}-\mathrm{C}_{10} \mathrm{HF}_{20} \mathrm{O}_{3}\right)_{2}\right]_{3}$ in a biphasic toluene/GALDEN ${ }^{\circledR} \mathrm{SV} 135$ system using the bench-scale apparatus (Figure 2) [10]. The reaction proceeded successfully for about $400 \mathrm{~h}$ to give cyclohexyl acetate in $>90 \%$ yield. A high turnover number (TON) of $>9000$ was attained for the Lewis acid catalysis [11] After $400 \mathrm{~h}$, yields of cyclohexyl acetate decreased due to leaching of the fluorous catalyst into the mobile organic phase. Consequently, we performed the continuous-flow acetylation of cyclohexanol using a one-tenth amount of $\mathrm{Yb}\left[\mathrm{N}\left(\mathrm{SO}_{2}-\mathrm{C}_{10} \mathrm{HF}_{20} \mathrm{O}_{3}\right)_{2}\right]_{3}$ (Figure 3). After $49 \mathrm{~h}$ and $77 \mathrm{~h}$, the leached fluorous catalyst was recovered from the organic phase in the product tank by extraction with SV135. When the recovered catalyst (which was confirmed to be as active as the fresh catalyst) was poured back into the reactor, the reaction again proceeded smoothly to give 
cyclohexyl acetate in high yield. After $107 \mathrm{~h}$, a TON of >21000 was attained [15]. It is expected that a much higher TON could be attained by continuous recovery of the leached fluorous catalysts.

Figure 2. Bench-scale continuous-flow reaction system.
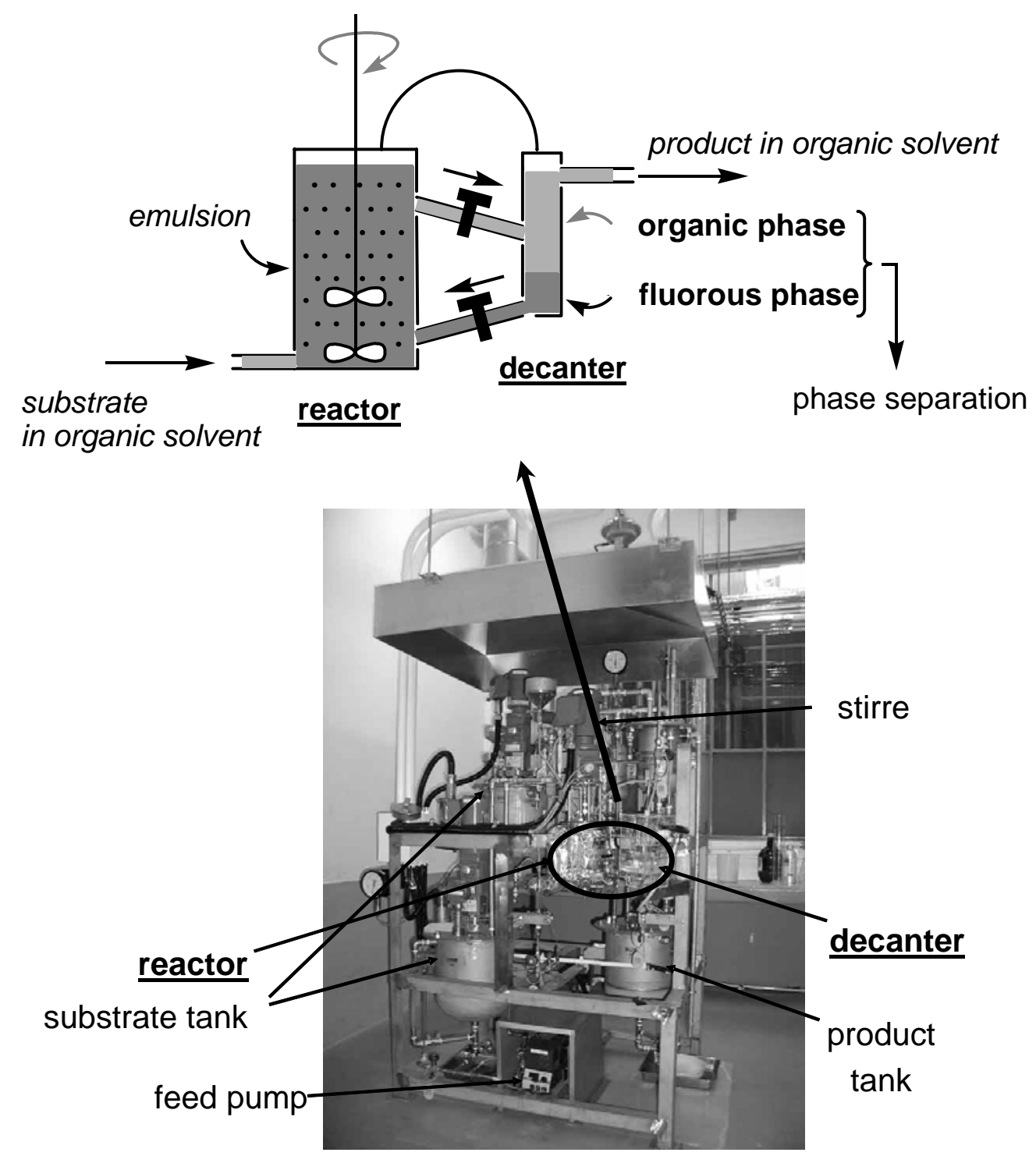

Figure 3. Continuous-flow acetylation of cyclohexanol.

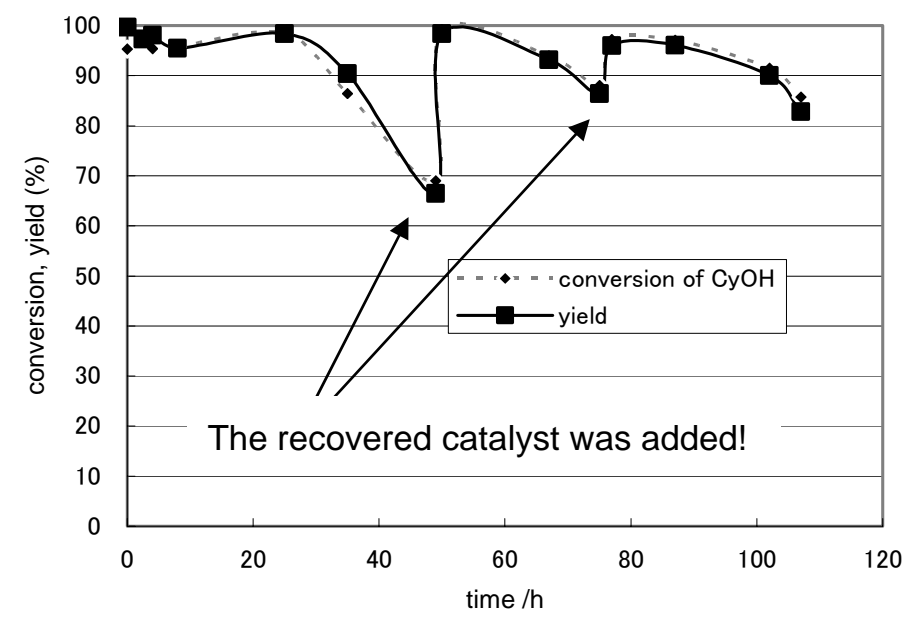


We also applied this method to a $\mathrm{Sn}\left[\mathrm{N}\left(\mathrm{SO}_{2}-n-\mathrm{C}_{8} \mathrm{~F}_{17}\right)_{2}\right]_{4}$-catalyzed Baeyer-Villiger reaction with aqueous hydrogen peroxide. As a result, a TON of 2200 was attained [11].

\section{Fluorous Silica Gel-Supported Lewis Acid Catalysts}

Fluorous silica gel has a perfluoroalkyl bonding phase and high affinity towards fluorous compounds. We therefore considered that our fluorous Lewis acid catalysts could be immobilized on fluorous silica gel, and this type of solid catalyst would be recoverable by simple filtration (Figure 4). It was expected that the catalytic reaction was taking place not only in an organic solvent but also in water [16]. In addition, we have previously reported aqueous reactions catalyzed by cyclodextrinepichlorohydrin copolymer-supported $\mathrm{Ln}\left[\mathrm{C}\left(\mathrm{SO}_{2}-n-\mathrm{C}_{4} \mathrm{~F}_{9}\right)_{3}\right]_{3}$, due to the affinity of cyclodextrin for the perfluorobutyl groups [17]. We examined the Baeyer-Villiger oxidation at a low-concentration $(<5$ $w t \%)$ of aqueous hydrogen peroxide catalyzed by fluorous silica gel-supported $\operatorname{Sn}\left[\mathrm{N}\left(\mathrm{SO}_{2}-n-\mathrm{C}_{8} \mathrm{~F}_{17}\right)_{2}\right]_{4}$ (Table 5).

Figure 4. Fluorous silica gel-supported Lewis acid catalyst model.

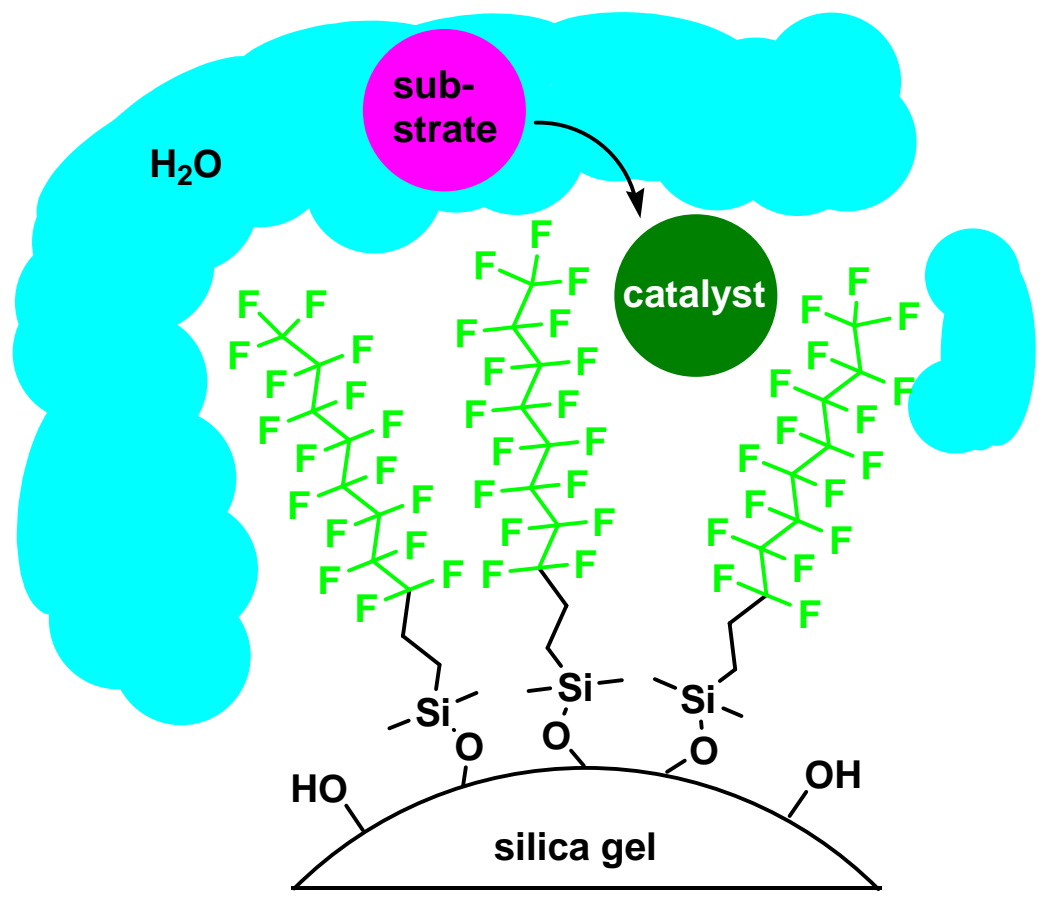

Fluorous silica gel-supported $\mathrm{Sn}\left[\mathrm{N}\left(\mathrm{SO}_{2}-n-\mathrm{C}_{8} \mathrm{~F}_{17}\right)_{2}\right]_{4}$ is a more active catalyst than any other silica gel-supported $\mathrm{Sn}\left[\mathrm{N}\left(\mathrm{SO}_{2}-n-\mathrm{C}_{8} \mathrm{~F}_{17}\right)_{2}\right]_{4}$. Additionally, it was found that octadecyl (ODS)-silica gel and normal silica gel-supported tin(IV) catalysts were not effective for recycling, while fluorous silica-gelsupported catalyst was recyclable; i.e. catalytic activity was maintained even after the 4th cycle reaction. Electron probe microanalysis (EPMA) confirmed that the fluorous tin(IV) catalyst was strongly immobilized on fluorous silica gel [7a], whereas, on the other hand, it was not effectively immobilized on either ODS-silica gel or on normal silica gel. 
Table 5. Baeyer-Villiger reactions catalyzed by silica gel-supported $\mathrm{Sn}\left[\mathrm{N}\left(\mathrm{SO}_{2}-n-\mathrm{C}_{8} \mathrm{~F}_{17}\right)_{2}\right]_{4}$.

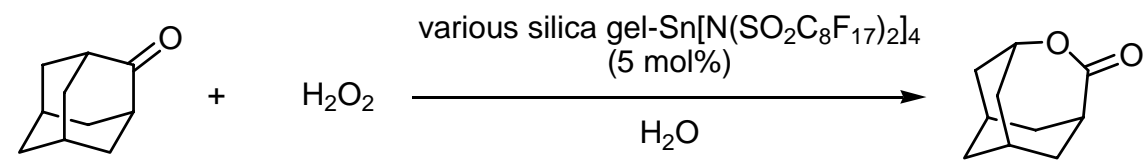

(1.1 equiv., 0.44 wt\%) $\quad 35^{\circ} \mathrm{C}, 16 \mathrm{~h}$

\begin{tabular}{|c|c|c|c|}
\hline catalyst & cycle $^{a}$ & \% yield y,c $^{\mathrm{b}}$ & \% selectivity ${ }^{\mathrm{c}, \mathrm{d}}$ \\
\hline fluorous $\mathrm{SiO}_{2-}$ & 1 & $79(87)$ & $100(89)$ \\
\hline \multirow[t]{3}{*}{$\mathrm{Sn}\left[\mathrm{N}\left(\mathrm{SO}_{2}-n-\mathrm{C}_{8} \mathrm{~F}_{17}\right)_{2}\right]_{4}$} & 2 & 75 (89) & $97(92)$ \\
\hline & 3 & $73(86)$ & $96(90)$ \\
\hline & 4 & $71(88)$ & $91(93)$ \\
\hline ODS $\mathrm{SiO}_{2-}$ & 1 & 60 & 88 \\
\hline \multirow{2}{*}{$\mathrm{Sn}\left[\mathrm{N}\left(\mathrm{SO}_{2}-n-\mathrm{C}_{8} \mathrm{~F}_{17}\right)_{2}\right]_{4}$} & 2 & 41 & 84 \\
\hline & 3 & 28 & 82 \\
\hline \multirow{3}{*}{$\begin{array}{c}\mathrm{SiO}_{2^{-}} \\
\mathrm{Sn}\left[\mathrm{N}\left(\mathrm{SO}_{2}-n-\mathrm{C}_{8} \mathrm{~F}_{17}\right)_{2}\right]_{4}\end{array}$} & 1 & 43 & 93 \\
\hline & 2 & 34 & 100 \\
\hline & 3 & 24 & 86 \\
\hline
\end{tabular}

${ }^{\mathrm{a}}$ The catalyst was recycled by simple filtration; ${ }^{\mathrm{b}}$ Calculated by GC analysis using $n$-nonane as an internal standard; ${ }^{\mathrm{C}}$ Values in parentheses were the results of the reactions at $25{ }^{\circ} \mathrm{C}$ using 10 equiv. of $\mathrm{H}_{2} \mathrm{O}_{2}$ (4 wt\%); ${ }^{\mathrm{d}}$ Molar ratio of formed lactone / converted 2-adamantanone.

Fluorous silica gel-supported fluorous Lewis acid catalysts were also effective for Diels-Alder reactions in water and direct esterification reactions in organic media. While our study was underway Bannwarth and co-workers reported the use of a fluorous silica gel-supported fluorous palladium(0) catalyst for the Sonogashira coupling [18].

\section{Supercritical Carbon Dioxide as a Reaction Medium}

The replacement of reaction media for homogeneous catalysis has been known to provide an opportunity to control reactions in terms of reactivity and selectivity due to the high gas miscibilities, greater diffusivities, clustering effects, and tunable solvent power by changing their density along with the pressure [19]. Supercritical carbon dioxide has been used as an environmentally benign reaction medium for transition metal-catalyzed hydroformylation [20], hydrogenation [21] and so on. On the other hand, the use of supercritical carbon dioxide for Lewis acid catalysis in terms of design and recyclability of Lewis acid catalysts is an important research topic [22].

We have developed fluorous Lewis acid catalysts bearing long perfluoroalkyl group chains such as perfluorooctyl groups as highly active catalysts. Since typical fluorous compounds are soluble in supercritical carbon dioxide [20-22], a homogeneous phase with the fluorous solvent is expected to immobilize fluorous catalysts. After the reaction, the fluorous solvent with the fluorous catalyst remains in the reaction vessel after releasing liquid carbon dioxide. Thus, the fluorous phase is expected to be recyclable (Figure 5a). Moreover, we examined another method for recycling Lewis acid catalysts that are insoluble in liquid carbon dioxide, even in the presence of reaction substrates and products (Figure 5b). We describe herein a method for recycling our fluorous Lewis acid catalysts in supercritical carbon dioxide [23]. 
Figure 5. Recycle methods for fluorous lanthanide catalysts using $\mathrm{scCO}_{2}$ as a reaction media: (a) fluorous/scCO $\mathrm{siph}_{2}$ biphic reaction; (b) without fluorous solvent.

(a)

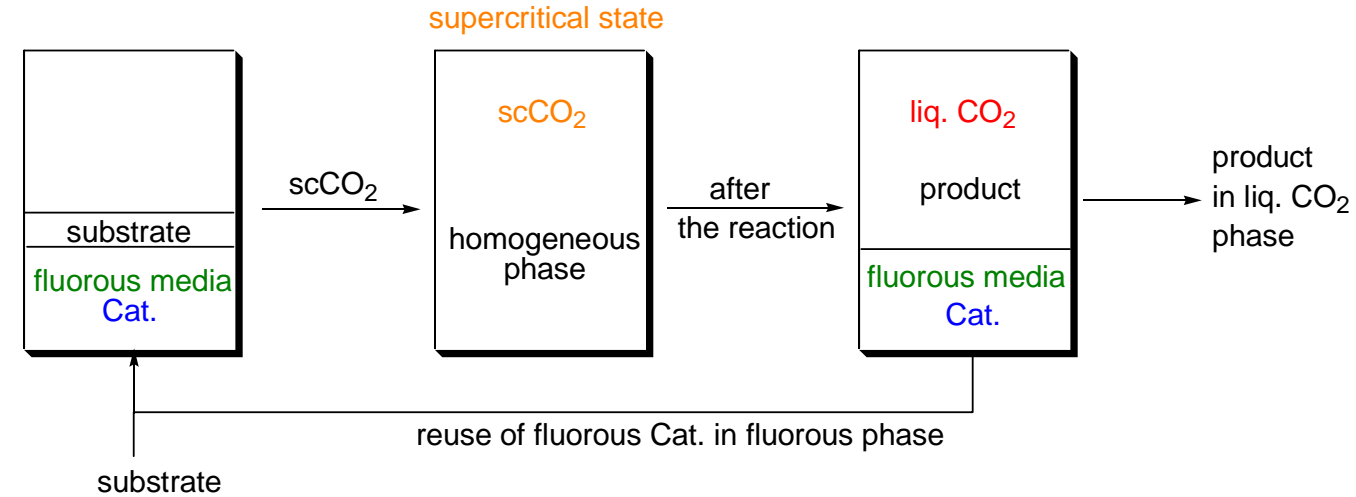

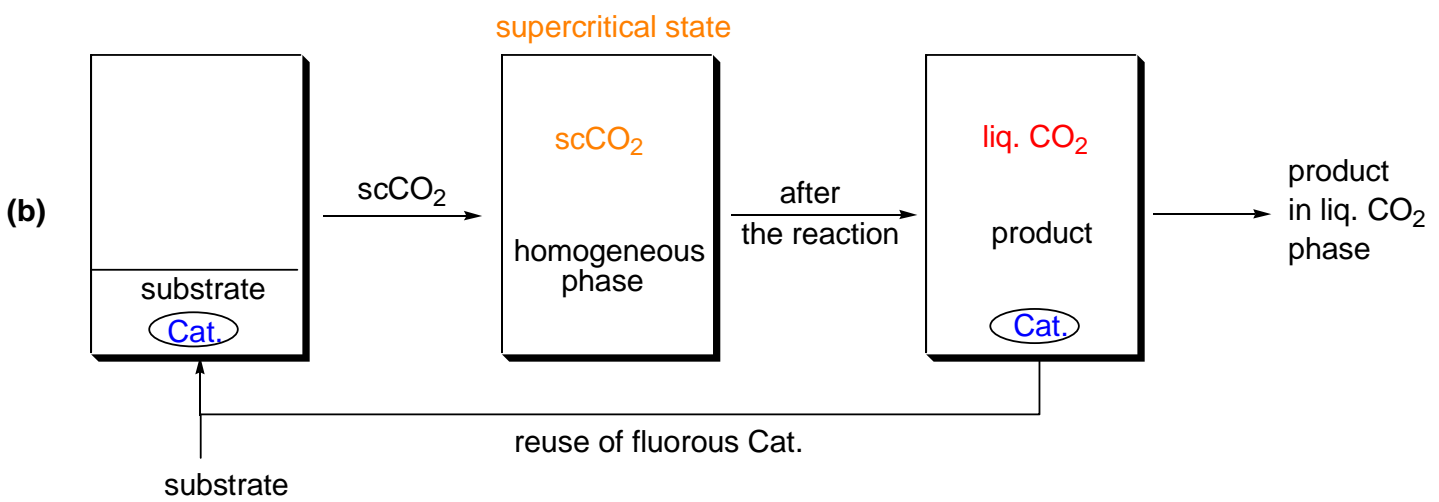

(a) Supercritical carbon dioxide/fluorous solvent system

We examined the catalytic activities of the fluorous Lewis acids using alcohol acylation in supercritical carbon dioxide/perfluorooctane as a probe reaction. The acetylation of cyclohexanol with 1.1 equiv. of acetic anhydride proceeded in the homogeneous phase involving a soluble fluorous phase immobilized fluorous catalyst above the critical point (Table 6).

Table 6. Fluorous biphasic acetylation in $\mathrm{scCO}_{2} / \mathrm{C}_{8} \mathrm{~F}_{18}$.

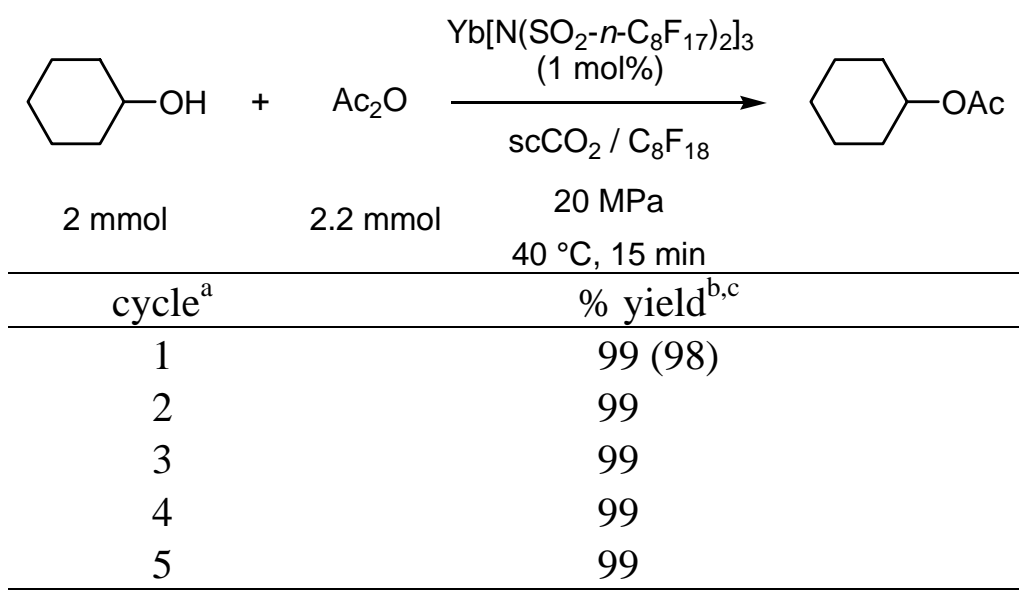

${ }^{\mathrm{a}}$ The catalyst in the fluorous phase was recycled; ${ }^{\mathrm{b}}$ Calculated by GC analysis using $n$-nonane as an internal standard; ${ }^{\mathrm{c}}$ Value in parenthesis refers to the isolated yield. 
After the reaction, the catalyst was soluble in the fluorous phase and the product was separated from the fluorous phase by extracting with an organic solvent. The isolated yield of the product was $98 \%$, whereas the yield of acetylation in supercritical carbon dioxide without the fluorous catalyst was only 3\%. Therefore, we may conclude that the fluorous catalyst is effective in supercritical carbon dioxide. The fluorous phase immobilized lanthanide catalyst was recyclable five times and no loss of catalytic activity was observed for the recovered catalyst.

\section{(b) Supercritical carbon dioxide system}

We also examined the acetylation of cyclohexanol in supercritical carbon dioxide catalyzed by the fluorous catalyst without a fluorous solvent. It was observed that $\mathrm{Yb}\left[\mathrm{N}\left(\mathrm{SO}_{2}-n-\mathrm{C}_{8} \mathrm{~F}_{17}\right)_{2}\right]_{3}$ catalyst was soluble in supercritical carbon dioxide $\left(40{ }^{\circ} \mathrm{C}, 10 \mathrm{MPa}\right.$ ) (Figure 6a). In contrast, the catalyst was deposited in liquid carbon dioxide below the critical point by lowering temperature and pressure $(-20$ ${ }^{\circ} \mathrm{C}, 6 \mathrm{MPa}$ ) even in the presence of the products (Figure 6b). Using this temperature-dependent solubility advantage of the fluorous catalyst, we examined its reuse [24].

Figure 6. Esterification in: (a) homogeneous phase under supercritical carbon dioxide; (b) heterogeneous phase under liquid carbon dioxide.

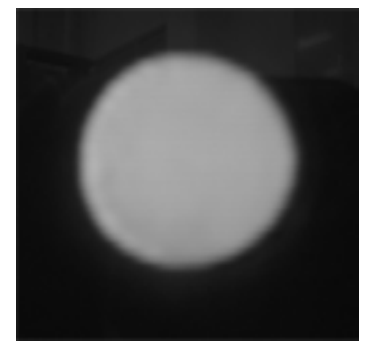

(a)

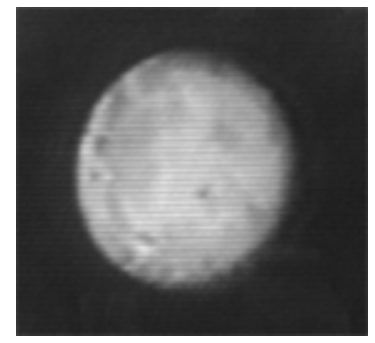

(b)

The acetylation of cyclohexanol with acetic anhydride catalyzed by $\mathrm{Yb}\left[\mathrm{N}\left(\mathrm{SO}_{2}-n-\mathrm{C}_{8} \mathrm{~F}_{17}\right)_{2}\right]_{3}$ or $\mathrm{Sc}\left[\mathrm{N}\left(\mathrm{SO}_{2}-n-\mathrm{C}_{8} \mathrm{~F}_{17}\right)_{2}\right]_{3}$ was performed in supercritical carbon dioxide (Table 7).

Table 7. Fluorous biphasic acetylation in $\mathrm{scCO}_{2}$.

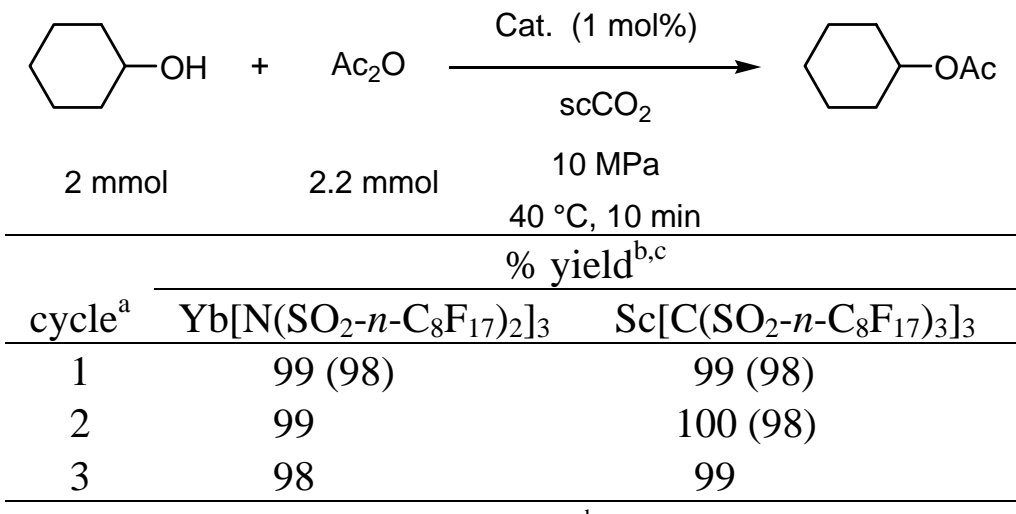

${ }^{\mathrm{a}}$ The residual catalyst was recycled; ${ }^{\mathrm{b}}$ Calculated by GC analysis using $n$-nonane as an internal standard; ${ }^{\mathrm{C}}$ Values in parentheses refer to the isolated yields. 
After the reaction, the reaction vessel was cooled to $-20^{\circ} \mathrm{C}$ to deposit the fluorous catalyst. The resultant liquid carbon dioxide was evacuated with products. The residual catalyst remained in the reaction vessel and was reused without isolation. The isolated yield was $98 \%$ using $\mathrm{Yb}$ (III) or Sc(III) catalyst. The lanthanide catalyst was recyclable three times and no loss of catalytic activity was observed with the recovered catalyst.

Next, the catalytic activities and recyclable use of the fluorous catalysts were examined for C-C bond forming reactions. The Friedel-Crafts acylation reaction is one of the most useful processes in organic synthesis. The reaction of anisole with 2 equiv. of acetic anhydride was also carried out in the presence of $\mathrm{Yb}$ (III) or $\mathrm{Sc}(\mathrm{III})$ catalyst (Table 8). As a result, it was noted that both catalysts were effective for the Friedel-Crafts acylation. After the reaction, the remaining catalyst was completely recovered and reused in supercritical carbon dioxide without isolation.

Table 8. Fluorous biphasic Friedel-Crafts acylation in $\mathrm{scCO}_{2}$.

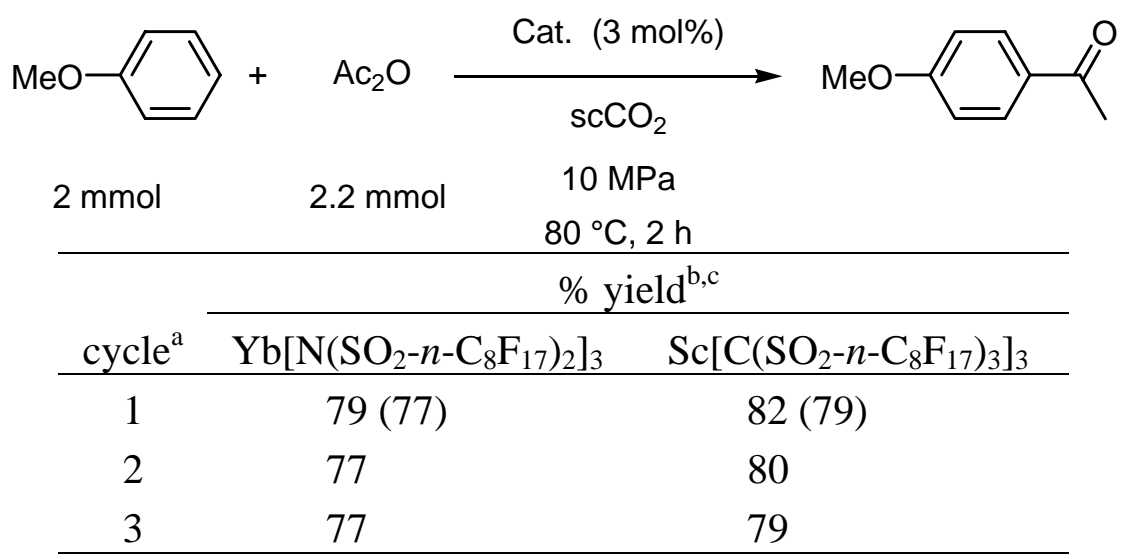

${ }^{\mathrm{a}}$ The residual catalyst was recycled; ${ }^{\mathrm{b}}$ Calculated by GC analysis using $n$-nonane as an internal standard; ${ }^{\mathrm{c}}$ Values in parentheses refer to the isolated yields.

\section{Conclusions}

We have developed various useful reactions catalyzed by novel fluorous Lewis acids $\mathrm{M}\left[\mathrm{N}\left(\mathrm{SO}_{2}-n\right.\right.$ $\left.\left.\mathrm{C}_{8} \mathrm{~F}_{17}\right)_{2}\right]_{\mathrm{n}}$ in a fluorous biphasic system, immobilized on fluorous silica gel, and in supercritical carbon dioxide. The catalysts were recyclable in many cases and this enables reduction of acidic wastes. We have established a continuous-flow reaction system based on the fluorous biphasic system for industrial processes. The fluorous catalytic reaction processes can be applied to synthesis of various products such as fine chemicals, pharmaceutical and pesticide intermediates, that are expected to come into practical use as useful technology for reduction of acidic wastes.

\section{Acknowledgements}

This work was mainly supported by New Energy and Industrial Technology Development Organization (NEDO) through the R\&D program for Process Utilizing Multi-Phase Catalytic Systems. This work was partially supported by Grant-in-Aid for Scientific Research (No. 16750087) from the Ministry of Education, Culture, Sports, Science and Technology, Government of Japan. 


\section{References and Notes}

1. For reviews see: a) Handbook of Fluorous Chemistry; Gladysz, J. A.; Curran, D. P.; Horváth, I. T., Eds.; Wiley-VCH: Weinheim, 2004; b) Fluorous Chemistry; Otera, J., Ed.; CMC Publishing: Tokyo, 2005.

2. Horváth, I. T.; Rábai, J. Science 1994, 266, 72-75.

3. Chem. Eng. News 2005, August 15, p 39.

4. For review: Kobayashi, S.; Sugiura, M.; Kitagawa, H.; Lam, W. W. L. Chem. Rev. 2002, 102, 2227-2302.

5. Koppel, I. A.; Taft, R. W.; Anvia, F.; Zhu, S.-Z.; Hu, L.-Q.; Sung, K.-S.; DesMarteau, D. D.; Yagupolskii, L. M.; Yagupolskii, Y. L.; Ignat’ev, N. V.; Kondratenko, N. V.; Volkonskii, A. Y.; Vlasov, V. M.; Notario, R.; Maria, P.-C. J. Am. Chem. Soc. 1994, 116, 3047-3057.

6. a) Nishikido, J.; Nakajima, H.; Saeki, T.; Ishii, A.; Mikami, K. Synlett 1998, 1347-1348; b) Nishikido, J.; Yamamoto, F.; Nakajima, H.; Mikami, Y.; Matsumoto, Y.; Mikami, K. Synlett 1999, 1990-1992.

7. For reviews: a) Nishikido, J.; Yoshida, A. J. Synth. Org. Chem., Jpn. 2005, 63, 144-153; b) Yoshida, A.; Hao, X.; Yamazaki, O.; Yamada, I.; Nishikido, J. In Fluorous Chemistry; Otera, J., Ed.; CMC Publishing: Tokyo, 2005; pp. 185-199.

8. a) Mikami, K.; Mikami, Y.; Matsumoto, Y.; Nishikido, J.; Yamamoto, F.; Nakajima, H. Tetrahedron Lett. 2001, 42, 289-292; b) Mikami, K.; Mikami, Y.; Matsuzawa, H.; Nishikido, J.; Yamamoto, F.; Nakajima, H. Tetrahedron 2002, 58, 4015-4021; c) Nishikido, J.; Yamamoto, F.; Nakajima, H. U. S. Patent, 6436866, 2002.

9. Hao, X.; Yoshida, A.; Nishikido, J. Tetrahedron Lett. 2005, 46, 2697-2700.

10. GALDEN ${ }^{\circledR}$ SV135 is a fluorous solvent containing ether oxygen atoms, purchased from Solvay Solexis K.K. (http://www.solvaysolexis.com/).

11. Yoshida, A.; Hao, X.; Nishikido, J. Green Chem. 2003, 5, 554-557.

12. For reviews: a) Otera, J. Esterification; Wiley-VCH: Weinheim, 2003; b) Otera, J. Chem. Rev. 1993, 93, 1449-1470.

13. Hao, X.; Yoshida, A.; Nishikido, J. Tetrahedron Lett. 2004, 45, 781-785.

14. a) Hao, X.; Yamazaki, O.; Yoshida, A.; Nishikido, J. Tetrahedron Lett. 2003, 44, 4977-4980; b) Hao, X.; Yamazaki, O.; Yoshida, A.; Nishikido, J. Green Chem. 2003, 5, 524-528.

15. Yoshida, A.; Hao, X.; Nishikido, J. 1st International Symposium on Fluorous Technologies (ISoFT’05), Bordeaux, July 2005; p. 59.

16. a) Yamazaki, O.; Hao, X.; Yoshida, A.; Nishikido, J. Tetrahedron Lett. 2003, 44, 8791; b) Yoshida, A.; Hao, X.; Yamazaki, O.; Nishikido, J. 1st International Symposium on Fluorous Technologies (ISoFT'05), Bordeaux, July 2005; p. 8.

17. Nishikido, J.; Nanbo, M.; Yoshida, A.; Nakajima, H.; Matsumoto, Y.; Mikami, K. Synlett 2002, 1613-1616.

18. Tzschucke, C. H.; Markert, C.; Glatz, H.; Bannwarth, W. Angew. Chem. Int. Ed. 2002, 41, 45004503. 
19. For reviews: a) Oakes, R. S.; Clifford, A. A.; Rayner, C. M. J. Chem. Soc., Perkin Trans. 1 2001, 917-941; b) Jessop, P. G.; Ikariya, T.; Noyori, R. Chem. Rev. 1999, 99, 475-494; c) Ikariya, T.; Noyori, R. In Transition Metal Catalysed Reactions; Murahashi, S.-I.; Davies, S. G., Eds.; Blackwell Science: Oxford, 1999; pp. 1-28; d) Jessop, P. G.; Leitner, W. Chemical Synthesis Using Supercritical Fluids; Wiley-VCH: Weinheim, 1999.

20. For recent examples: a) Franciò, G.; Wittmann, K.; Leitner, W. J. Organomet. Chem. 2001, 621, 130-142; b) Osuna, A. M. B.; Chen, W.; Hope, E. G.; Kemmitt, R. D. W.; Paige, D. R.; Stuart, A. M.; Xiao, J.; Xu, J. J. Chem. Soc., Dalton Trans. 2000, 4052-4055; c) Sellin, M. F.; ColeHamiltone, D. J. J. Chem. Soc., Dalton Trans. 2000, 1681-1683; d) Meehan, N. J.; Sandee, A. J.; Reek, J. N. K.; Kamer, P. C. J.; van Leeuwen, P. W. N.; Poliakoff, M. Chem. Commum. 2000, 1497-1498; e) Palo, D. R.; Erkey, C. Organometallics 2000, 19, 81-86; f) Franciò, G.; Leitner, W. Chem. Commun. 1999, 1663; g) Koch, D.; Leitner, W. J. Am. Chem. Soc. 1998, 120, 13398-13404.

21. a) Brown, R. A.; Pollet, P.; McKoon, E.; Eckert, C. A.; Liotta, C. L.; Jessop, P. G. J. Am. Chem. Soc. 2001, 123, 1254-1255; b) Lange, S.; Trautner, P.; Woelk, K.; Leitner, W. Chirality 2000, 12, 450-457; c) Kainz, S.; Brinkmann, A.; Leitner, W.; Pfaltz, A. J. Am. Chem. Soc. 1999, 121, 64216429; d) Xiao, J.; Nefkens, S. C. A.; Jessop, P. G.; Ikariya, T.; Noyori, R. Tetrahedron Lett. 1996, 37, 2813-2816; e) Burk, M. J.; Feng, S.; Gross, M. F.; Tumas, W. J. Am. Chem. Soc. 1995, 117, 8277-8278.

22. For Lewis acid-catalyzed reactions in supercritical fluids, see: a) Komoto, I.; Kobayashi, S. Org. Lett. 2002, 4, 1115-1118; b) Fukuzawa, S.-I., Metoki, K.; Komuro, Y.; Funazukuri, T. Synlett 2002, 134-136; c) Komoto, I.; Kobayashi, S. Chem. Commum. 2001, 1842-1843; d) Fukuzawa, S.-I.; Matsuzawa, H.; Metoki, K. Synlett 2001, 709-711; e) Tsuchiya, T.; Odashima, K.; Kobayahi, S. Chem. Lett. 2000, 178-179; f) Kawada, A.; Mitamura, S.; Matsuo, J.-I.; Tsuchiya, T.; Kobayashi, S. Bull. Chem. Soc. Jpn. 2000, 73, 2325-2333; g) Mikami, K.; Matsukawa, S.; Kayaki, Y.; Ikariya, T. Tetrahedron Lett. 2000, 41, 1931-1934; h) Oakes, R. S.; Heppenstall, T. J.; Shezad, N.; Clifford, A. A.; Rayner, C. M. Chem. Commum. 1999, 1459-1460.

23. Nishikido, J., Kamishima, M.; Matsuzawa, H.; Mikami, K. Tetrahedron 2002, 58, 8345-8349.

24. Fluorous catalysts as a solid in organic solvents were reviewed, see: a) Wende, M.; Meier, R.; Gladysz, J. A. J. Am. Chem. Soc. 2001, 123, 11490-11491; b) Ishihara, K.; Kondo, S.; Yamamoto, H. Synlett 2001, 1371-1374.

(c) 2006 by MDPI (http://www.mdpi.org). Reproduction is permitted for noncommercial purposes. 